\title{
Perioperative oral management has a positive effect in maintaining serum albumin and lymphocyte count through cancer surgery
}

T. Gibo ${ }^{1}$, H. Otagiri ${ }^{1}$, Y. Hakoyama ${ }^{2}$, S. Yamada ${ }^{1}$, H. Kurita ${ }^{1}$.

1: Department of Dentistry and Oral Surgery, Shinshu University School of Medicine, Matsumoto, Japan.

2: Oral and Maxillofacial Surgery, Aizawa Hospital, Matsumoto, Japan.

\section{Introduction}

- Perioperative oral management is expected to reduce systemic/local infection and some other adverse events caused by oral/dental bacteria.

- It is also expected to maintain and improve oral functions, which may produce good patient's immunonutritional condition.

\section{Objectives}

- The purpose of this retrospective study is to assess whether perioperative oral management had a positive effect in maintaining nutritional and immune condition through cancer surgery.

- Prognostic nutritional index (PNI) has been used to assess immunonutritional condition.

\section{Material and Methods}

\section{Patients}

- 181 patients who underwent cancer surgery for digestive or urinary organ in 2016 were available in the study.

- Of these, 63 patients underwent perioperative oral management (POM group), and other 118 patients did not (control group).

\section{Evaluation of transition of PNI}

- Prognostic nutritional index (PNI, calculated from serum albumin and lymphocyte count; Ono et al, 1984) has an advantage that it can easily be calculated from normal blood test.

$\mathrm{PNI}=0.005 \times \mathrm{TLC}+10 \times \mathrm{Alb}$

TLC : total lymphocyte count $\left(\mathrm{mm}^{3}\right)$

ALB : albumin (g / dl)

- PNI was evaluated through cancer surgery (pre- and postoperatively) and compared between the groups.

\section{Results}

\begin{tabular}{|c|c|c|c|c|}
\hline \multicolumn{1}{|c|}{ POM or control } & $\begin{array}{c}\text { Age } \\
\text { (average) }\end{array}$ & $\begin{array}{c}\text { Male } \\
(\mathrm{n})\end{array}$ & $\begin{array}{c}\text { Female } \\
(\mathrm{n})\end{array}$ & $\begin{array}{c}\text { Total } \\
(\mathrm{n})\end{array}$ \\
\hline Total & & & & \\
\hline $\begin{array}{c}\text { POM } \\
\text { control }\end{array}$ & 67.0 & 42 & 21 & 63 \\
\hline $\begin{array}{c}\text { Digestive } \\
\text { POM } \\
\text { control }\end{array}$ & 68.1 & 90 & 28 & 118 \\
\hline $\begin{array}{c}\text { Urinary } \\
\text { POM }\end{array}$ & 69.3 & 27 & 20 & 47 \\
\hline control & 69.7 & 17 & 10 & 27 \\
\hline
\end{tabular}

Table.1 Patients characteristics (Age· Gender)

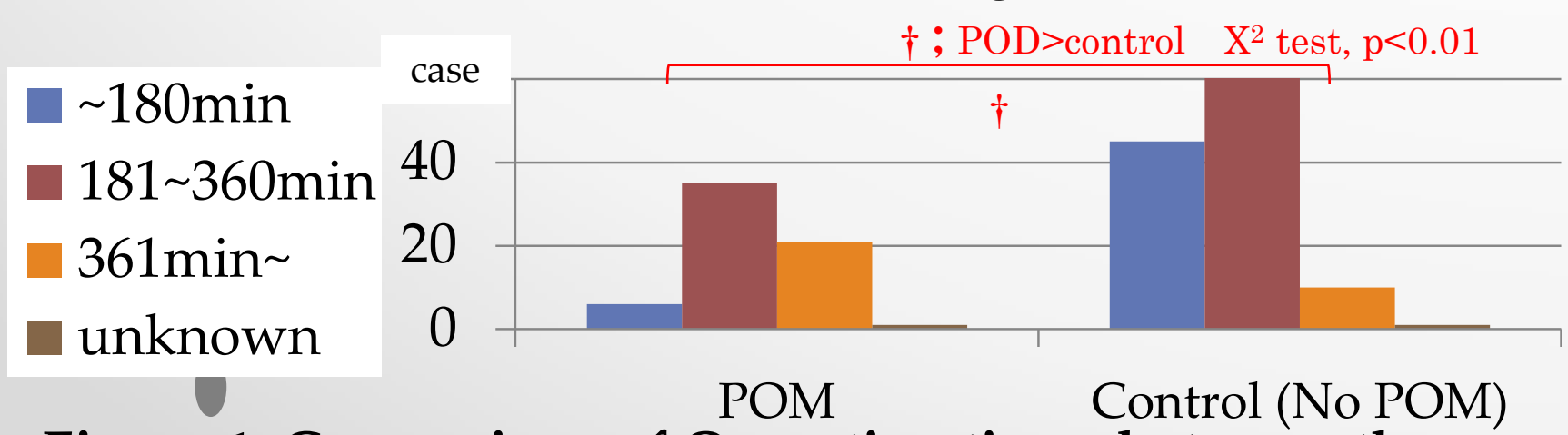

Figure.1 Comparison of Operating times between the groups

$\begin{array}{lr} & \text { case } \\ \square 10 \mathrm{ml} & 80 \\ 11 \sim 100 \mathrm{ml} & 60 \\ 101 \mathrm{ml} & 40 \\ & 20 \\ & 0\end{array}$

Figure.2 Comparison of Intraoperative bleeding volume

$\begin{array}{lr}\text { PNI : } & \text { case } \\ \sim 40 & 80 \\ & 60 \\ 41 \sim 50 & 40 \\ 51 \sim & 20 \\ & 0\end{array}$

unknown

Figure.3 Comparison of Preoperative PNI

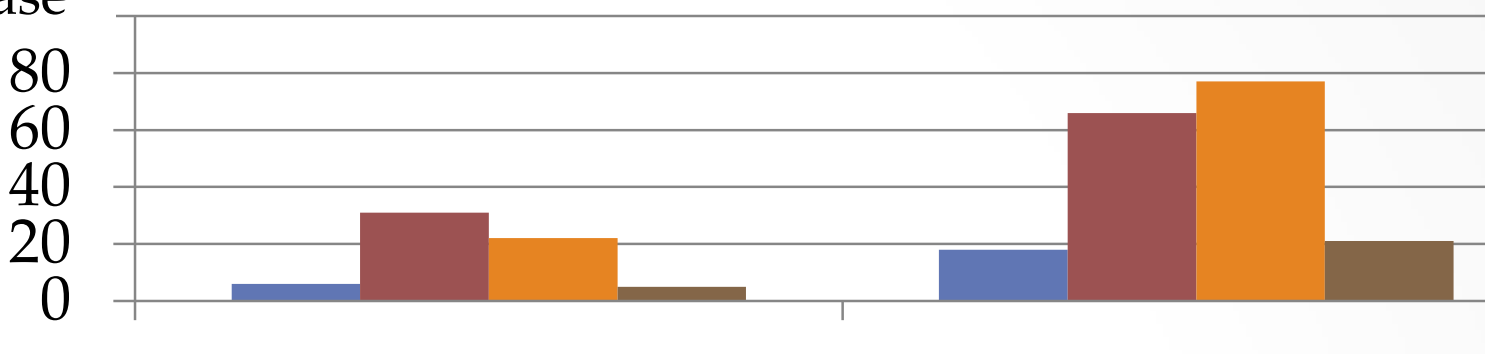
100

50

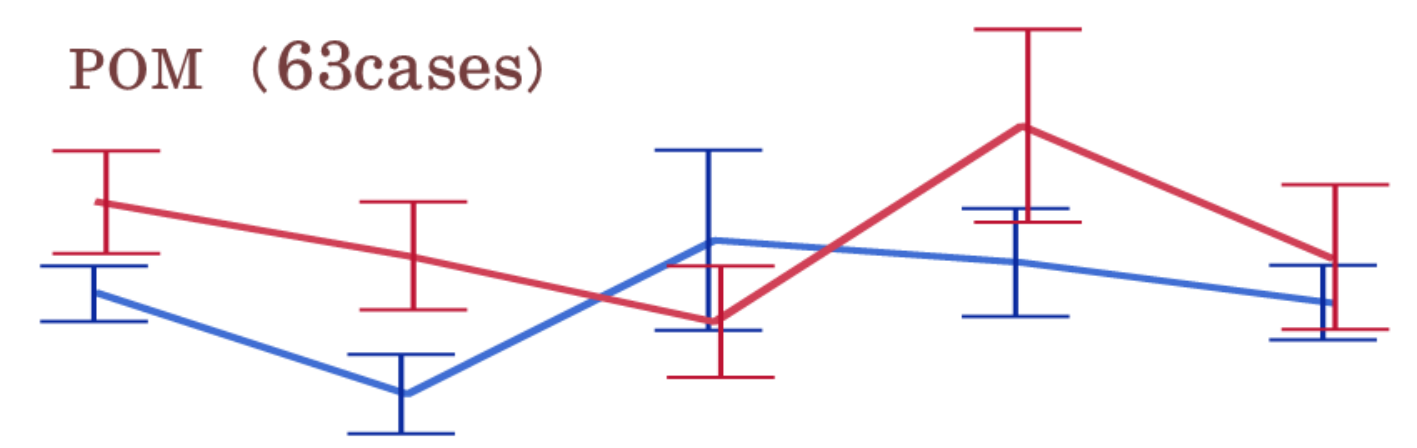

control (118cases)

0 Perioperative POD 3-7 POD 8-14 POD 15-28 POD29-42 Figure. 4 Comparison of Preoperative PNI

100 POM (23cases)

50

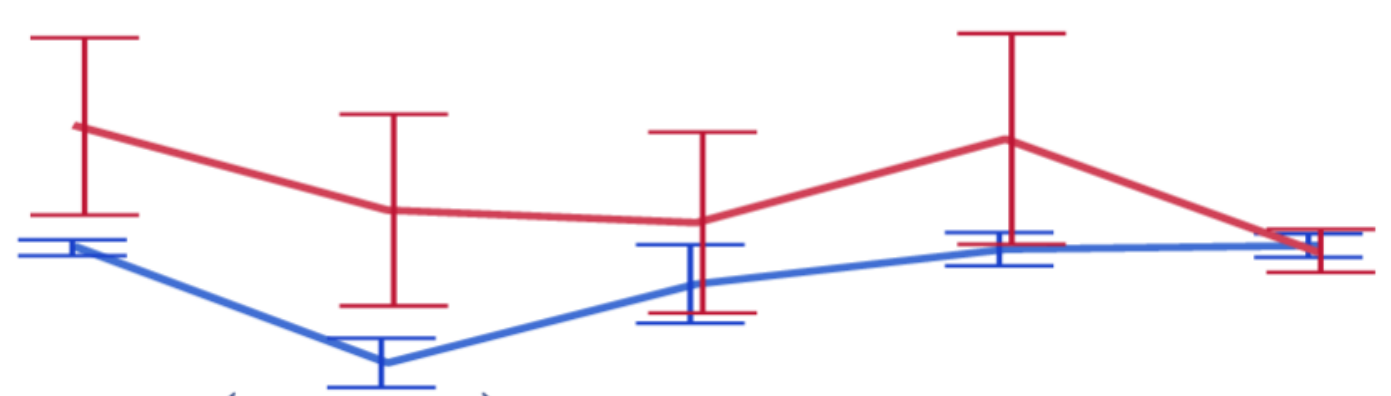

Control (91cases) POD $>$ control least-squares method, $\mathrm{p}<0.05$

0 Perioperative POD 3-7 POD 8-14 POD 15-28 POD 29-42

Figure.5 Perioperative PNI of patient who resume ingestion within 3 days after the surgery

- There were significant differences in comparison of operating times (Fig.1) and intraoperative bleeding volume (Fig.2), and it suggests that the POM group tends to undergo more invasive surgery.

- No significant difference was observed in comparison of preoperative PNI (Fig.3).

- PNI of the POM group tended to reveal less decline and better recovery after cancer surgery than that of the control group(Fig.4). If patients who resume ingestion within three days after the surgery were compared, the difference was more statistically significant(Fig.5).

\section{Conclusions}

- The results of this study suggested that perioperative oral management might have a positive effect on maintaining serum albumin level and lymphocyte count through cancer surgery. 